\title{
BIOSYNTHESIS OF PHOSPHATIDIC ACID IN RAT BRAIN VIA ACYL DIHYDROXYACETONE PHOSPHATE
}

\author{
AmiYa K. HajRa and Caryl Burke \\ Neuroscience Laboratory, Mental Health Research Institute and the \\ Department of Biological Chemistry, University of Michigan, Ann Arbor, \\ MI 48109, U.S.A.
}

(Received 30 August 1977. Accepted 5 January 1978)

\begin{abstract}
The enzymes for the biosynthesis of phosphatidic acid from acyl dihydroxyacetone phosphate were shown to be present in rat brain. These enzymes were mainly localized in the microsomal fraction of 12-14 day old rat brains. The brain microsomal acyl CoA:dihydroxyacetone phosphate acyl transferase (EC 2.3.1.42), exhibited a broad $\mathrm{pH}$ optimum between $\mathrm{pH} 5$ and 9 with maximum activity at pH 5.4. $K_{m}$ for DHAP at pH 5.4 was $0.1 \mathrm{~mm}$ and $V_{\max }$ was $0.86 \mathrm{nmol} / \mathrm{min} / \mathrm{mg}$ of microsomal protein. The corresponding microsomal enzyme for the glycerophosphate pathway (acyl CoA: sn-glycerol-3phosphate acyl transferase EC 2.3.1.15) was shown to have a different $\mathrm{pH}$ optimum ( $\mathrm{pH}$ 7.6). On the basis of the differences in $\mathrm{pH}$ optima, differential effects of sodium cholate in the enzymes and a common substrate competition study, these acyl transferases were postulated to be two different microsomal enzymes.

Acyl DHAP:NADPH oxidoreductase (EC 1.1.1.101) in brain microsomes was found to be quite specific for NADPH as cofactor, being able to utilize NADH only at very high concentrations. This enzyme exhibited a $K_{m}$ of $8.6 \mu \mathrm{m}$ with NADPH and $V_{\max }$ of $0.81 \mathrm{nmol} / \mathrm{min} / \mathrm{mg}$ protein. The presence of these two enzymes and the known presence of 1-acyl-sn-glycesol-3-phosphate:acyl CoA acyl transferase in brain (FLEMING \& HAJRA, 1977) demonstrated the biosynthesis of phosphatidic acid in brain via acyl dihydroxyacetone phosphate. Phosphatidic acid was shown to form when dihydroxyacetone phosphate, acyl COA, NADPH and other cofactors were incubated together with brain microsomes. Further properties of the enzymes and the probable importance of the presence of this pathway in brain were discussed.
\end{abstract}

Phosphatidic acid (1,2-diacyl-sn-glycerol-3-phosphate) has been shown to be a precursor of all glycerides and phosphoglycerides in different systems (KENNEDY, 1962; VAN DEN BOSCH, 1974). A number of workers have shown that phosphatidate in brain is biosynthesized by the acylation of sn-glycerol-3-phosphate (G-3-P) ${ }^{1}$ (MCMurray et al., 1957; MárTensSON \& KANFer, 1968; SÁNChez DE Jiminez \& CleLAND, 1969; KUWAHARA, 1972; POSSMAYER et al., 1972). Recently, in liver and other systems, we have shown that phosphatidic acid is also biosynthesized by an alternate pathway via 1-acyl dihydroxyacetone-3-phosphate (acyl DHAP) (HAJRA, 1968b, 1977). Acyl DHAP, which is formed by a direct acylation of DHAP with acyl COA (acyl CoA:DHAP acyl transferase EC 2.3.1.42) (HAIRA, 1968b; LABELLE \& HAJRA, 1972b) is enzymatically reduced by NADPH (acyl DHAP:NADPH oxidoreductase EC 1.1.1.101) (Hajra \& AgranofF, 1968b; LaBelle \& HaJra, 1972a) to 1-acyl-sn-G-3-P (lysophosphatidic acid). Lysophosphatidate is then converted to phosphatidate by the widely distributed acyl transferase, acyl CoA:1-acyl-G-3-P acyl transferase (FLEMING \& Harra, 1977). Preliminary studies show that the enzymes of the acyl DHAP pathway are present in

Abbreviations used: G-3-P-sn-glycerol-3-phosphate DHAP-dihydroxyacetone phosphate. brain (LaBelle \& Hajra, 1972a, $b$; Pollack et al., 1975). However, a detailed study shows that the distribution of the enzymes and their properties are somewhat different than the acyl DHAP pathway enzymes in liver. These results are presented here. A comparison of the acyl CoA:DHAP acyl transferase and the well studied acyl CoA:G-3-P acyl transferase in brain is also made.

\section{MATERIALS AND METHODS}

$\mathrm{H}_{3}{ }^{32} \mathrm{PO}_{4}$ and $\left[1{ }^{14} \mathrm{C}\right]$ palmitic acid were obtained from New England Nuclear (Cambridge, MA.). Coenzyme A, ATP, D-glucose-6-phosphate, cytochrome c, NADH, NADPH, 2'3'cyclic AMP, 2(-p-iodophenyl)-3(-p-nitrophenyl-5-phenyl tetrazolium chloride, DL-glycerol-3-phosphate, 2[N-morpholino]ethane sulfonic acid (MES), $N$-2-hydroxyethylpiperazine- $N^{\prime}$-2-ethane sulfonic acid (HEPES). Tris, and morpholinopropane sulfonic acid (MOPS) were from Sigma Chemical Corp. (St. Louis, MO.). Palmitoyl CoA, stearoyl CoA, oleoyl CoA, and linoleoyl COA were purchased from P-L Biochemicals (Milwaukee, WI.). Ficoll (MW $\sim 400,000$ ) came from Pharmacia Fine Chemicals. Fatty acid poor bovine serum albumin (Fr. V) was from Miles Laboratories (Elkhart, IN). Other materials were obtained as described previously (LaBelle \& HajRa, 1972a,b; Fleming \& HavRA, 1977).

Linoleoyl COA, arachidonoyl CoA, docosatetraenoyl CoA (n-6) and docosahexaenoyl CoA (n-3) were chemically synthesized from CoA and acyl chloride (SEubert, 1960; 
Oxuyama et al., 1969; Fleming \& Hajra, 1977). DHAP was regenerated from the dimethyl ketal by mild acid hydrolysis (BALLOU \& FisheR, 1956) and used without removing the methanol. $\left[{ }^{32} \mathrm{P}\right]$ DHAP was prepared by the enzymatic phosphorylation of dihydroxyacetone using [ $\gamma^{32}$ P]ATP (HNRA, 1968b). The intermediate $\left[\gamma^{-32} \mathrm{P}\right]$ ATP, which was made from ${ }^{32} \mathbf{P}_{\mathrm{i}}$ by an enzymatic exchange reaction (GLYNN \& ChapPEL, 1964), was not purified as described before (HalkA, 1968b), but was used directly for the subsequent phosphorylation reaction. The $\left[{ }^{32} \mathrm{P}\right] \mathrm{DHAP}$ was purified by a barium salt fractionation method (MEyerhof \& LOHMANN, 1934) and the details of this modified procedure are described here. The incubation mixture contained triethanolamine $\mathrm{HCl}$ buffer $(\mathrm{pH} 8.00$, $60 \mathrm{~mm}$ ), ATP (5 mM), $\mathrm{MgCl}_{2}(6 \mathrm{~mm}), \mathrm{NaOH}(12 \mathrm{~mm})$, cysteine $(2 \mathrm{mM})$, 3-phosphoglycerate $(2 \mathrm{mM})$, D-glyceraldehyde-3-P dehydrogenase (EC 1.2.1.12) (1 mg protein) and 3-phosphoglycerate kinase (EC 2.7.2.3)(0.2 mg protein), and ${ }^{32} \mathrm{P}_{\mathrm{i}}$ (carrier free, $2-10 \mathrm{mCi}, 99 \%$ radionuclidic purity) in a total vol of $5 \mathrm{ml}$. After a $90 \mathrm{~min}$ incubation at room temperature, $0.5 \mathrm{ml}$ of $0.5 \mathrm{M}$-dihydroxyacetone, $20 \mu \mathrm{l}$ glycerokinase (EC 2.7.1.30) (0.1 $\mathrm{mg}$ protein) and $0.25 \mathrm{ml}$ of $0.1 \mathrm{M}$-ATP were added to the mixture and the solution was further incubated for $2 \mathrm{~h}$ at room temperature. The reaction was stopped by adding $0.5 \mathrm{ml}$ of $1 \mathrm{M}$-barium acetate. The mixture was cooled in ice water for $30 \mathrm{~min}$ and then centrifuged $(1000 \mathrm{~g}, 10 \mathrm{~min})$ to remove the barium salt of ATP, ADP and inorganic phosphate. The clear supernatant was removed to another tube and the barium salt precipitate was washed with $1 \mathrm{ml}$ cold water. To the combined supernatant $10 \mathrm{vol}$ of ethanol-acetone (1-1) were added and, after mixing, the tube was kept at $-20^{\circ} \mathrm{C}$ overnight. The barium salt of DHAP was collected by centrifugation and decantation of the supernatant. After the removal of the last trace of solvent under a gentle stream of $\mathrm{N}_{2}$, the precipitate was dissolved in $2 \mathrm{ml}$ water. The solution (sometimes turbid) was passed through a small column $(4 \times 0.5 \mathrm{~cm})$ of Dowex- $50 \mathrm{H}^{+} \mathrm{X} 4$ to remove the barium. The free acid form of DHAP was eluted with 4-6 $\mathrm{ml}$ distilled water. The purity of the radioactive DHAP was checked using high voltage paper electrophoresis (HajRa \& Agranoff, 1968a). As described previously, (HARA, 1968a) the $\left[{ }^{32} \mathrm{P}\right]$ DHAP was found to contain ${ }^{32} \mathrm{P}_{i}$ $(5-10 \%)$ but not any $\left[{ }^{32} \mathrm{P}\right]$ ATP. The yield was generally $70-90 \%$ of the ${ }^{32} \mathrm{P}_{\mathrm{i}}$ used for the incubation. The $\left[{ }^{32} \mathrm{P}\right] \mathrm{DHAP}$ was stored frozen $\left(-20^{\circ} \mathrm{C}\right)$ in the free acid form and only $3-5 \%$ decomposition (to ${ }^{32} \mathrm{P}_{\mathrm{i}}$ ) was observed after a period of 2 months. $s n\left[{ }^{32} \mathbf{P}\right]$ glycerol-3-phosphate (G-3-P) was prepared by the same method, except that instead of dihydroxyacetone, glycerol was used in the incubation mixture. The chemical amounts of both radioactive and non-radioactive DHAP and G-3-P were measured enzymatically using glycerol-3-phosphate dehydrogenase (EC 1.1.1.8) (BÜCHER \& HOHORST, 1963; HOHORST, 1963).

The rat brain subcellular fractions were prepared from 12 to 15 day old male rats and were fractionated by differential and density gradient centrifugation essentially as described by EichBerg et al. (1964). The brains were removed after $\mathrm{CO}_{2}$ asphyxiation and homogenized with $9 \mathrm{vol}$ of $0.32 \mathrm{M}$-sucrose- $0.1 \mathrm{~mm}$-EDTA in a glass homogenizer with rotating Teflon pestle (A. H. Thomas). The homogenate was centrifuged at $1000 \mathrm{~g}$ for $10 \mathrm{~min}$. The supernatant $\left(S_{1}\right)$ was removed carefully and centrifuged at $18,000 \mathrm{~g}$ for 30 min to separate the crude mitochondria $\left(\mathrm{P}_{2}\right)$ from the crude microsomes $\left(S_{2}\right)$. The $S_{2}$ fraction was centrifuged at $100,000 \mathrm{~g}$ for $30 \mathrm{~min}$ and the microsomal pellet was washed once with sucrose-EDTA $\left(3 \times 10^{6} \mathrm{~g} \cdot \mathrm{min}\right)$. Using a discontinuous density gradient, the $P_{2}$ fraction was further fractionated into myelin, synaptosomes and mitochondria in the manner described by EICHBERG et al. (1964). All particulate fractions were rehomogenized in $0.32 \mathrm{M}$-sucrose and the suspensions were stored frozen at $-20^{\circ} \mathrm{C}$. Specially purified mitochondria were prepared in a Ficoll density gradient as described by CLARK \& NicKLAS (1970). Pure heavy myelin was prepared by the method of Jungalwala \& Dawson (1971). Marker enzymes for various fractions were used to determine the relative purity of each fraction and also to help determine the subcellular localization of the enzymes under study. NADPH-cytochrome $c$ reductase as a marker for microsomes (Miller \& Dawson, 1972) was assayed using the method of Williams \& KAMIN (1962). Lactate dehydrogenase was assayed according to HARWOOD \& HAWTHORNE (1969). 2',3'-Cyclic nucleotidase, a marker enzyme for myelin, was assayed using a procedure described by Olafson et al. (1969). The DHAP and G-3-P acyl transferases were assayed using an incubation mixture that contained $75 \mathrm{~mm}$ buffer (acetate buffer at pH 5.4 and Tris- $\mathrm{HCl}$ at $\mathrm{pH} 7.4$ ) $8 \mathrm{~mm}-\mathrm{MgCl}_{2}, 8 \mathrm{~mm}-\mathrm{NaF}, 2 \mathrm{mg}$ bovine serum albumin (fatty acid poor), $0.1 \mathrm{mg}$ palmitoyl CoA, $0.1 \mathrm{mM}-\left[{ }^{32} \mathrm{P}\right] \mathrm{DHAP}$ or [ ${ }^{32}$ P]G-3-P $(3000-10,000$ c.p.m. $/ \mathrm{nmol})$, enzyme in the desired amount (usually $0.1-0.2 \mathrm{mg}$ protein), and water to make a final vol of $1.2 \mathrm{ml}$. This is the standard incubation mixture referred to throughout the text. The tubes were incubated at $37^{\circ} \mathrm{C}$ and the reaction was stopped after a specified time period (usually $15 \mathrm{~min}$ ) by adding $4.5 \mathrm{ml}$ chloroform-methanol $(1: 2)$. The lipid was extracted using an acidic Bligh and Dyer method (Bligh \& DYeR, 1959) by adding $1.5 \mathrm{ml}$ more $\mathrm{CHCl}_{3}$ and $1.5 \mathrm{ml}$ $2 \mathrm{M}-\mathrm{KCl}-0.2 \mathrm{M}-\mathrm{H}_{3} \mathrm{PO}_{4}$ (HAJRA, 1974). After centrifugation, the upper aqueous layer was removed and the lower layer was washed twice with $5 \mathrm{ml}$ of a theoretical upper phase (which contained $\mathrm{CHCl}_{3}$-methanol-water, 1:12:12) and a few drops of $6 \mathrm{~N}-\mathrm{H}_{3} \mathrm{PO}_{4}$. A portion of the washed lower layer was used to determine the radioactivity (LABELLE \& HANRA, 1972b).

Acyl[ ${ }^{32}$ P]DHAP was prepared enzymatically by acylating [ $\left.{ }^{32} \mathrm{P}\right] \mathrm{DHAP}$ with fatty acyl $\mathrm{CoA}$. The radioactive lipid was purified by chromatography on silicic acid (HAJRA, 1968a). The acyl DHAP:NADPH oxidoreductase was assayed in an incubation mixture containing $75-100 \mathrm{~mm}$ buffer, $8 \mathrm{~mm}-\mathrm{NaF}, 0.1 \mathrm{~mm}-\mathrm{NADPH}, 0.1-0.7 \mathrm{mg}$ protein, $45 \mu \mathrm{M}$-acyl $\left[{ }^{32} \mathrm{P}\right]$ DHAP (2200 c.p.m./nmol), $30 \mathrm{mg}$ Triton-X-100, and water to make $1.2 \mathrm{ml}$. Acyl $\left[{ }^{32} \mathrm{P}\right]$ DHAP and Triton-X-100 from chloroform solutions were dried down together and then emulsified in Tris- $\mathrm{HCl}$ buffer (pH 7.5, $0.3 \mathrm{~m}$ ) by sonication for $30 \mathrm{~s}$ in an Ultrasonic Cleaner, Model 8845-3 made by Cole-Parmer (Chicago, IL) and subsequent heating at $50^{\circ} \mathrm{C}$ for a few minutes. Aliquots of the emulsion were then added to the mixture of enzymes, buffer, etc. which had been preincubated for $5 \mathrm{~min}$ at $37^{\circ} \mathrm{C}$. The reaction was started by adding the reduced pyridine nucleotide solution to the mixture, which was then incubated at $37^{\circ} \mathrm{C}$ for $10 \mathrm{~min}$. Blanks containing no NADPH and no enzyme were also run. The lipids were extracted by the acidic Bligh and Dyer method described above. The washed lower layer containing the lipid was dried under $\mathrm{N}_{2}$ and an aliquot was put on a TLC plate which was developed in $\mathrm{CHCl}_{3}$-methanol-acetic acid-5\% aqueous $\mathrm{NaHSO}_{3}(25: 10: 3: 1)$ (HaJRA, 1968b) to separate the product (lysophosphatidate, $R_{f}=0.33$ ) from the substrate (acyl DHAP, $R_{F}=0.2$ ). The radioactive compounds 
on the plate were localized by radioautography and the $\left[{ }^{32} \mathrm{P}\right]$-labeled lipid spots on TLC were scraped out and counted (LABelle \& HAJRA, 1972a). The relative radioactivity in the lysophosphatidate spot was compared to that of acyl DHAP and used to calculate the enzyme activity. Sometimes the reductase activity was determined by using B- $\left[4{ }^{3} \mathrm{H}\right]$ NADPH as described previously (LABELLE \& HAJRA, 1972). Other methods are the same as described previously (LaBelle \& HajRa, 1972a, $b$; Fleming \& HAJRA, 1977).

\section{RESULTS}

Requirements for the biosynthesis of acyl DHAP in brain homogenate

When acyl CoA, $\left[{ }^{32}\right.$ P]DHAP and other cofactors were incubated with whole brain homogenate, a $\left[{ }^{32} \mathrm{P}\right]$-labeled lipid was formed which was characterized as acyl $\left[{ }^{32} \mathrm{P}\right]$ DHAP (see later, Fig. 6). The requirements for the formation of acyl DHAP in brain are shown in Table 1 . It is seen that acyl CoA (or an acyl CoA generating system) was absolutely necessary for the formation of the labeled lipid. $\mathrm{Mg}^{2+}, \mathrm{NaF}$ and bovine serum albumin were found to be stimulatory (Table 1), similar to what was found in the liver mitochondrial system (HAJRA, 1968a).

\section{Subcellular distribution of DHAP acyl transferase}

The subcellular fractions were assayed for the presence of various marker enzymes as well as for the DHAP acyl transferase and GP acyl transferase. Relative specific activities for each fraction and each enzyme were calculated and plotted against per cent total protein as described by DEDUvE et al. (1955). Figure I shows that activity for the DHAP acyl transferase was present in all subcellular fractions, but was enriched in the microsomal fraction. The data for NADPH-cytochrome $c$ reductase, the microsomal marker enzyme, show microsomal contamination in all the other subcellular fractions, making it difficult to determine whether the acyl transferase was present in those fractions or not. Therefore, purer mitochondria (Clark \& NiCKLAS, 1970) and myelin (JungalWALA \& Dawson, 1971) were prepared. Activity for the acyl transferase in the purer mitochondria $(0.013 \mathrm{nmol} / \mathrm{min} / \mathrm{mg})$ and myelin $(0.001 \mathrm{nmol} / \mathrm{min} / \mathrm{mg})$ was very low compared to that found in microsomes $(0.48 \mathrm{nmol} / \mathrm{min} / \mathrm{mg})$. On the basis of these data, the microsomal fraction was determined to contain the bulk of the acyl transferase activity, and it was utilized in all subsequent work.

\section{Properties of acyl CoA:DHAP acyl transferase}

The enzyme activity was measured at various $\mathrm{pH}$ and the peak activity $(0.48 \mathrm{nmol} / \mathrm{min} / \mathrm{mg}$ microsomal protein) was found at $\mathrm{pH} 5.4$ with a broad shoulder of activity up to pH 8.5 (Fig. 2). The DHAP acyl transferase activity was also found to be influenced by the nature of the buffer used. For example, Trismaleate buffer and $\beta$-glycerophosphate buffer between pH 5-7 strongly inhibited the reaction, whereas imidazole buffer between $\mathrm{pH}$ 6.5-8.5 somewhat stimulated $(5-15 \%)$ the enzyme. For comparison, Fig. 2 also includes the $\mathrm{pH}$ vs activity profile for the G-3-P acyl transferase in microsomes. The G-3-P acyl transferase was found to have a maximum activity $(0.6 \mathrm{nmol} /$ $\mathrm{min} / \mathrm{mg}$ microsomal protein) at $\mathrm{pH} 7.5$ as reported previously (KUWAHARA, 1972). All subsequent incubations for DHAP acyl transferase were done at $\mathrm{pH} 5.4$ and 7.4, and at pH 7.4 for the G-3-P acyl transferase. The assay used for this enzyme was found to be reproducible within $\pm 5 \%$ when the same batch of microsome was used. However, more variation $( \pm 10 \%)$ was observed in the different batches of microsomes obtained from rats of the same age group. The enzyme activity changed with the age of the animals (see later).

The DHAP acyl transferase activity was linear up to $0.15 \mathrm{mg}$ microsomal protein and fifteen minutes incubation time at pH 5.4 and 7.4. With increasing concentration of DHAP and keeping the palmitoyl CoA concentration constant, the reaction rate followed Michaelis-Menten kinetics as shown in Fig. 3. The $K_{m}$ for DHAP was $0.1 \mathrm{mM}$ and the $V_{\max }$ was $0.86 \mathrm{nmol} / \mathrm{min} / \mathrm{mg}$ of microsomal protein at $\mathrm{pH} 5.4$ At $\mathrm{pH} 7.6$, the corresponding figures were $K_{m}=0.08 \mathrm{mM}$ and $V_{\max }=0.55 \mathrm{nmol} / \mathrm{min} / \mathrm{mg}$

TABle 1. Requirements for the acylation of DHAP IN WHOLE bRain HOMOGENATE

\begin{tabular}{lc}
\hline \multicolumn{1}{c}{ Conditions } & Product formed (c.p.m.) \\
\hline Whole system & 2299 \\
Whole - palmitoyl CoA & 0 \\
Whole - palmitoyl CoA + ATP & \\
+ fatty acid + CoA & 1568 \\
Whole - MgCl & 1806 \\
Whole - Bovine serum albumin & 1275 \\
Whole - NaF & 1062 \\
Whole with boiled enzyme & 0
\end{tabular}

The whole system contained $75 \mathrm{~mm}-\mathrm{Tris}-\mathrm{HCl}$ pH $7.4,8 \mathrm{~mm}-\mathrm{MgCl}_{2}$, $8 \mathrm{~mm}-\mathrm{NaF}, 2 \mathrm{mg}$ bovine serum albumin, $0.1 \mathrm{mg}$ palmitoyl CoA, $0.1 \mathrm{~mm}-\left[{ }^{32} \mathrm{P}\right]$ DHAP $\left(10^{4} \mathrm{c.p} . \mathrm{m} . / \mathrm{nmol}\right)$, and $0.3 \mathrm{mg}$ whole brain homogenate in $0.25 \mathrm{M}$-sucrose in a final volume of $1.2 \mathrm{ml}$. The incubation and extraction procedures were described in the text.

* This enzyme fraction was heated for $10 \mathrm{~min}$ at $100^{\circ} \mathrm{C}$ before use. 


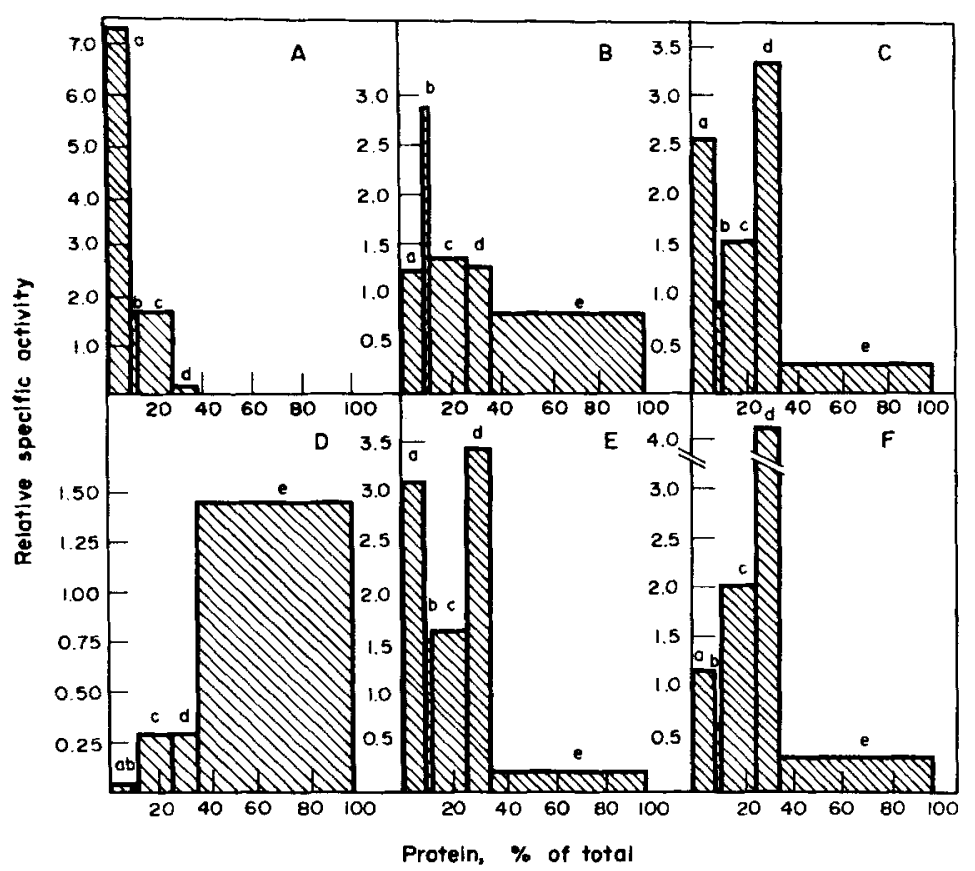

FiG. 1. Subcellular distribution of acyl transferases and marker enzymes. Fourteen day old rat brains were fractionated (See the text for details) into mitochondria (a), light myelin (b), synaptosomes (c), microsomes (d) and cytosol (e). Protein and the activities of various enzymes were determined in each fraction (see Methods) and the relative specific activities are plotted here. A, Succinate-2(-p-iodophenyl)-3-p-nitrophenyl-5-phenyl tetrazolium chloride reductase; $B, 2^{\prime}, 3^{\prime}$-cyclic nucleotidase; $C$, NADPH-cytochrome $c$ reductase; D, lactate dehydrogenase; E, G-3-P acyl transferase; F, DHAP acyltransferase.

Because of the formation of micelles at high concentration, an accurate $K_{m}$ for palmitoyl CoA could not be determined. An apparent $K_{m}$ of $31 \mu \mathrm{M}$ for palmitoyl $\mathrm{CoA}$ was found in the presence of $0.10 \mathrm{mg}$ of bovine serum albumin.

\section{Reduction of acyl DHAP by NADPH}

Acyl DHAP: NADPH oxidoreductase was found to be distributed in all the rat brain subcellular fractions, including the microsomal fraction. (See later Fig. 6.) Figure 4 shows the rate of acyl DHAP reduction in the brain microsomal fraction with increasing amounts of NADPH and NADH as coenzymes. $K_{m}$ for NADPH is $8.6 \mu \mathrm{M}$ and $V_{\max }=0.81 \mathrm{nmol} / \mathrm{min} / \mathrm{mg}$ protein. For comparison, NADH was substituted for NADPH and the $K_{m}(740 \mu \mathrm{M})$ and $V_{\max }(0.57 \mathrm{nmol} /$ $\mathrm{min} / \mathrm{mg}$ ) were determined. Figure 5 shows that the reductase has optimum activity between $\mathrm{pH} 6.5$ and 7.5. The reduction was found to be linear up to $1.5 \mathrm{mg}$ protein and $15 \mathrm{~min}$ incubation.

${ }^{1}$ A faint unidentified radioactive spot which was sometimes seen on the radioautogram migrated between phosphatidate and lysophosphatidate (lanes 2 and 5, Fig. 6). This spot has the same $R_{F}$ as phosphatidyl glycerol in this solvent system.

\section{Characterization of the products}

The radioactive lipid formed from $\left[{ }^{32} \mathrm{P}\right] \mathrm{DHAP}$ and acyl CoA was characterized as acyl $\left[{ }^{32}\right.$ P]DHAP by its comigration on TLC with synthetic palmitoyl DHAP in two different solvent systems $\left[\mathrm{CHCl}_{3}\right.$ methanol:acetic acid:water, 25:10:3:1 and $\mathrm{CHCl}_{3}$ methanol:acetic acid:5\% aqueous $\mathrm{NaHSO}_{3}$, 25:10:3:1] (HAJRA \& AGRANOFF, 1968a; HaJRA, $1968 a)$ and also by its conversion to ${ }^{32} P_{i}$ on alkaline methanolysis and to acyl[ $\left.{ }^{32} \mathrm{P}\right] \mathrm{G}-3-\mathrm{P}$ on treatment with $\mathrm{NaBH}_{4}$ (Hajra and AgranofF, 1968a). The same product was formed when non-radioactive DHAP was incubated with $\left[1-{ }^{14} \mathrm{C}\right]$ palmitic acid, ATP, CoA and other cofactors (see Table 1). Figure 6 shows that a single radioactive product, i.e. acyl $\left[{ }^{32} \mathrm{P}\right]$ DHAP was formed in brain microsomes when $\left[{ }^{32} \mathrm{P}\right] D H A P$ was incubated with acyl CoA (lane 1). The enzymes for the reduction of acyl DHAP to form lysophosphatidate and stibsequent acylation to phosphatidic acid were also shown to be present in the rat brain microsomal fraction. Addition of NADPH to the standard incubation mixture produced radioactive lipids which migrated with acyl G-3-P and phosphatidic acid (lane 2). ${ }^{1}$ If acyl DHAP was incubated with NADPH under the proper conditions, lysophosphatidate was formed (lane 4), but not 


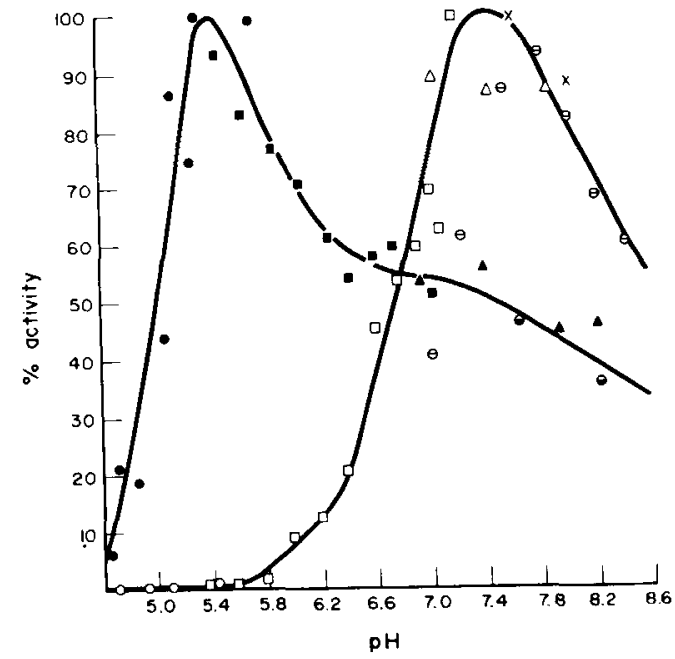

Fig. 2. The rate of acylation of DHAP (solid) and G-3-P (open) in brain microsomes as a function of $\mathrm{pH}$. The incubation mixture was the same as described in Table 1 , except $0.2 \mathrm{mg}$ microsomal protein were used and the buffer was varied as follows: acetate buffer ( $O \&$ ) between pH 4.7 and 5.7, 2[N-Morpholino]ethane sulfonic acid (MES) buffer ( $\square \&$ \& ) between pH 5.5-7.0, Morpholinopropane sulfonic acid (MOPS) buffer $(\triangle \& \Delta)$ from 6.0 to $8.2, \mathrm{Tris}-\mathrm{HCl}(\Theta \& \Theta)$ between $\mathrm{pH} 6.9-8.2$, and $N-2-$ hydroxyethyl piperazine- $N^{\prime}$-2-ethane sulfonic acid (HEPES) buffer $(x-x)$ from $\mathrm{pH}$ 7.6-8.2. The mixture was incubated for $15 \mathrm{~min}$ at $37^{\circ} \mathrm{C}$ and the radioactive lipid was determined as described in the text. The relative activities (per cent of maximum activity) of the enzymes were plotted for comparison.

phosphatidic acid since the acyl CoA generating system was not present in the mixture. Lane 5 shows that the enzymes for the acylation of G-3-P to form phosphatidic acid are also present in rat brain microsomes, and that monoacyl G-3-P and diacyl G-3-P are formed by the acylation of G-3-P.

Specificity of acylation towards long chain acyl CoAs

As found in the guinea pig liver system (HaJra, 1968a), the brain microsomal enzyme has the highest activity with palmitoyl CoA (Table 2). However, in contrast to the liver mitochondrial system, the brain acyl transferase was found to have some activity towards oleoyl CoA $(18: 1)$ and linoleoyl CoA (18:2) (Table 2). The enzyme does not accept arachidonoyl CoA (20:4), docosatetraenoyl CoA $(22: 4)$ or docosahexaenoyl CoA $(22: 6)$, which are the predominant endogenous polyunsaturated fatty acids in brain.

Comparison of G-3-P acyl transferase and DHAP acyl transferase

To check whether G-3-P acyl transferase and DHAP acyl transferase are the same enzyme in brain microsomes, experiments were done to test the competition between the two substrates for one enzyme (DIXON \& WeBB, 1964). This was studied by checking

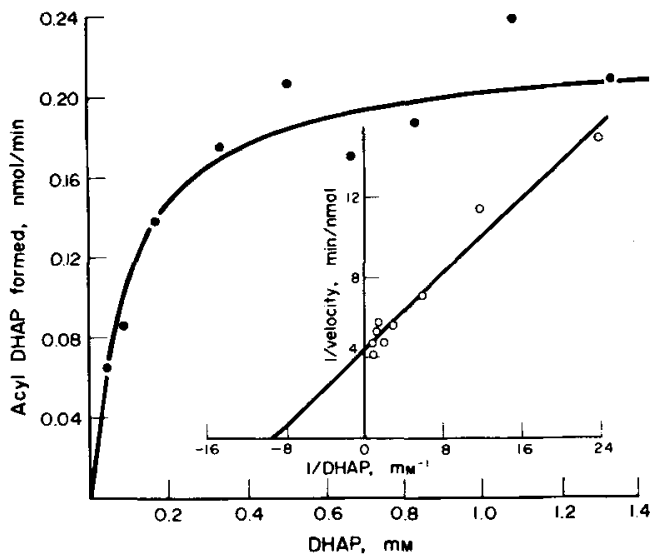

FIG. 3. Effect of increasing $\left[{ }^{32} \mathrm{P}\right] \mathrm{DHAP}$ on the rate of DHAP acyltransferase activity. $0.1 \mathrm{mg}$ Palmitoyl CoA was present in the incubation mixture, which was the same as described in Methods ( $\mathrm{pH}$ 5.4) with the DHAP concentration being varied as indicated. The extraction and counting procedures are described in the text.

the inhibition of the acylation of the radioactive substrate by an increasing concentration of the other (non-radioactive) substrate. As is seen in Fig. 7, the acylation of $\left[{ }^{32}\right.$ P]DHAP was not inhibited by G-3-P at pH 5.4 and only slightly inhibited at pH 7.4. On the other hand, the acylation of $\left[{ }^{32} \mathrm{P}\right] \mathrm{G}-3-\mathrm{P}$ at $\mathrm{pH} 7.4$ was inhibited by an increasing concentration of nonradioactive DHAP (Fig. 7). A differential effect of the detergent sodium cholate towards the two acyl transferases was also observed. Figure 8 shows that sodium cholate inhibited G-3-P acylation in whole brain homogenate at all concentrations. However, sodium cholate stimulated the DHAP acylation at low concentration $(<2 \mathrm{~mm})$ and inhibited the reaction only at higher concentrations.

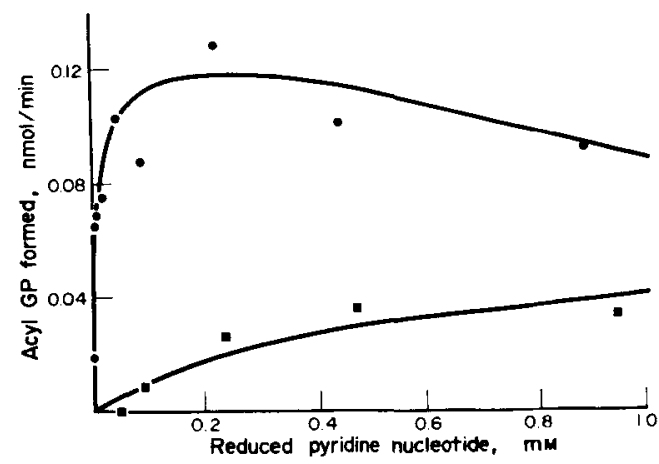

Fig. 4. Effect of increasing NADH and NADPH concentration on the rate of acyl DHAP: NADPH oxidoreductase activity. The incubations were carried out as described in Methods using acyl [ $\left.{ }^{32} \mathrm{P}\right]$ DHAP as substrate and varying the concentration of reductant, either NADPH or NADH ( - - $)$ ), as indicated. The assay procedure was the same as described under Methods. 


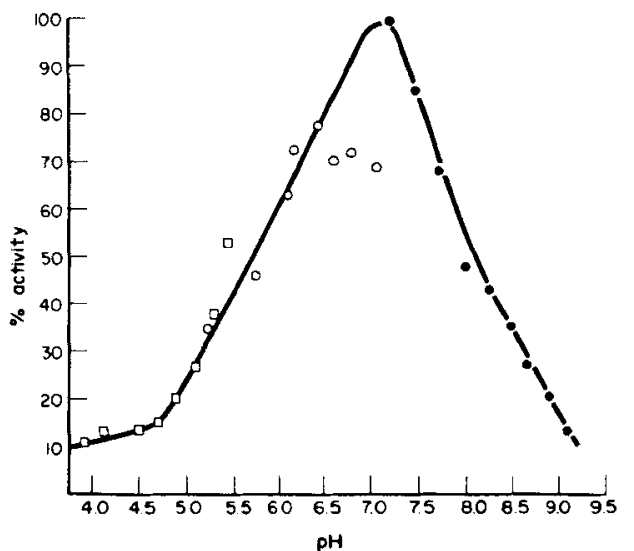

Fig. 5. Effect of pH on the activity of acyl DHAP: NADPH oxidoreductase. Using acetate buffer (口-D), MES buffer $\left(\mathrm{O}_{-} \mathrm{O}\right)$, and Tris- $\mathrm{HCl}$ buffer $(-\infty)$ and acyl $\left[{ }^{32} \mathrm{P}\right]$ DHAP as substrate, the activity of the oxidoreductase at various $\mathrm{pH}$ was determined. The assay conditions and determination of radioactive product were described in Methods, and percent of maximal activity was plotted.

\section{Change in brain acyl transferase activity with age}

In whole rat brain homogenate, the specific activity of DHAP acyl transferase was found to be fairly constant in rats from 3 to 18 days old $(0.1 \mathrm{nmol} / \mathrm{min} / \mathrm{mg}$ of protein). Thereafter, the activity of the enzyme rapidly declined to a level about $40-50 \%$ of the initial level in $\mathbf{3 0}$ day old rats, then remained fairly constant at that level up to the age of 90 days. The G-3-P acyl transferase activity was very high in the 3 day old rats $(0.22 \mathrm{nmol} / \mathrm{min} / \mathrm{mg}$ protein) and declined to a value of $0.12 \mathrm{nmol} / \mathrm{min} / \mathrm{mg}$ at 12 days. After 18 days, the activity declined further until, at 30 days, $30-50 \%$ of the activity found in the 18 day old rats remained. Activity was fairly constant thereafter up to 90 days.

\section{DISCUSSION}

The results presented above show that the two key enzymes of the acyl DHAP pathway for the biosynthesis of phosphatidic acid, i.e. acyl CoA:DHAP acyl transferase and acyl DHAP:NADPH oxidoreductase, are present in the brain microsomal system. It has been previously shown that 1-acyl-G-3-P:acyl CoA acyl transferase activity is also present in rat brain microsomes (FLEMING \& HAJRA, 1977). It is clearly seen in Fig. 6 that when DHAP is incubated with acyl CoA, NADPH and other cofactors, phosphatidic acid along with lysophosphatidic acid and acyl DHAP are formed. The properties of the acyl

\footnotetext{
${ }^{2}$ Recent work from this laboratory shows that in liver this enzyme has a pH-activity profile similar to that given in Fig. 2 when palmitoyl $\operatorname{CoA}$ is directly used for acylation (C. L. Jones \& A. K. Hajra, unpublished work).
}

CoA:DHAP acyl transferase in brain are similar to those described for the enzyme in liver (HAJRA, 1968a; LABelle \& HaJRA, 1968b). However, in contrast to the enzyme in liver, the brain enzyme is seen to be mainly localized not in mitochondria but in the microsomal fraction (Fig. 1). Comparison with the NADPH-cytochrome $c$ reductase shows some differences between the distributions of DHAP acyl transferase and this microsomal marker enzyme in brain subcellular fractions (Fig. 1). It is possible that DHAP acyl transferase is mainly localized not in microsomes but in some other cellular compartment which sediments down with microsomes upon differential centrifugation. Recent work from this laboratory shows that the corresponding liver enzyme is highly enriched in the peroxisomal fraction (microbody) of liver (JoNEs \& HaJRA, 1977). Peroxisomes have not been described in brain; however, catalase-containing small particles, termed 'microperoxisomes', have been shown to exist in brain (Novikoff et al., 1973; GAUNT \& DEDUVE, 1976). The microperoxisomes may contain the brain acyl transferase as well, and may sediment down with microsomes upon conventional differential centrifugation (Gaunt \& DeDuve, 1976). Preliminary work from our laboratory shows that DHAP acyl transferase activity in brain is more enriched in a heavy microsomal fraction $\left(1.8 \times 10^{5} \mathrm{~g} \mathrm{~min}-2.5\right.$ $\left.\times 10^{5} \mathrm{~g} \mathrm{~min}\right)$ than in the light microsomal fraction $\left(2.5 \times 10^{5} \mathrm{~g} \mathrm{~min}-3 \times 10^{6} \mathrm{~g} \mathrm{~min}\right)($ A. K. Hajra \& C. Howlett, unpublished work).

The brain DHAP acyl transferase has a surprisingly low pH optimum (pH 5.4) with a broad shoulder of activity up to $\mathrm{pH} 8$. Previously, this enzyme in liver was reported to have no activity below pH 6.5 (HAJRA, 1968a). However, that conclusion was based on an assay using an acyl CoA generating system (fatty acid, ATP, CoA) which was inactive at low $\mathrm{pH}^{2}$ In contrast to the high activity found for DHAP acyl transferase at low $\mathrm{pH}, \mathrm{G}-3-\mathrm{P}$ acyl transferase exhibits a high pH optimum and has no activity at $\mathrm{pH} 5.4$ in the same microsomal fraction (Fig. 2).

The brain microsomal fraction also has the acyl DHAP:NADPH oxidoreductase activity (Figs. 4 and 6). As shown previously (LABELLE \& HAJRA, 1972a) this enzyme is fairly specific for NADPH, and NADH can act as a coenzyme only at a very high concentration (Fig. 4). A number of workers have reported that NADH can also act as a coenzyme for the reductase (PULEo et al., 1970; WYKLE et al., 1972; LAMB \& FALLON, 1976). However, indirect methods, i.e. using DHAP and not acyl DHAP as substrate, have been used to demonstrate the acyl DHAP reductase activity with NADH. The activity found in these systems could be explained partially by the probable presence of NADH-linked glycerol-3-phosphate dehydrogenase in the incubation system. When direct comparisons are made using acyl DHÄP, NADPH is always found to be fairly specific for the reduction of acyl and alkyl DHAP (LABELLE \& HAJRA, 1972; ChaE et al., 1973). 


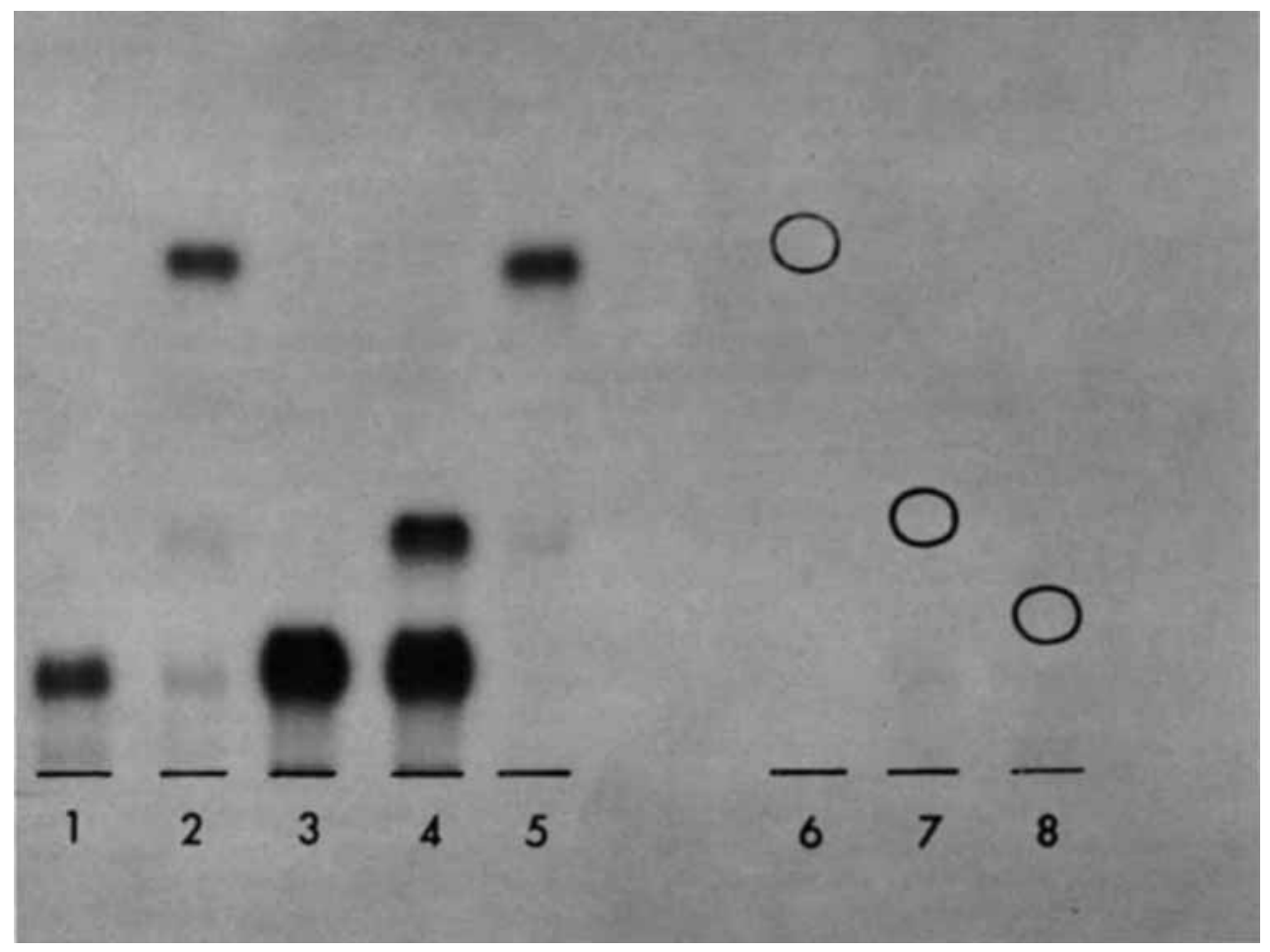

FIG. 6. Radioautograph of TLC plate showing radioactive products formed enzymatically from $\left[{ }^{32}\right.$ P $]$ DHAP and acyl $\left[{ }^{32}\right.$ P $]$ DHAP. (1) The incubation mixture contained $\left[{ }^{32} \mathbf{P}\right]$ DHAP as substrate and the standard ingredients (see text) at $\mathrm{pH} 7.5$ and $0.15 \mathrm{mg}$ brain microsomal protein. It was incubated for $15 \mathrm{~min}$ at $37^{\circ} \mathrm{C}$ and extracted as described in the text. The entire lower layer was evaporated under a stream of nitrogen and spotted on a silica gel TLC plate, then developed in chloroform-methanol-acetic acid $-5 \%$ aqueous sodium bisulfite $(25: 10: 3: 1)$ to a height of $10 \mathrm{~cm}$. The radioactive products were located by radioautography as shown. (2) $0.1 \mathrm{mg}$ NADPH was added to the incubation mixture described in (1). (3) Acyl[ $\left.{ }^{32} \mathrm{P}\right]$ DHAP $(80 \mathrm{nmol}$ and $2500 \mathrm{c.p} . \mathrm{m} . / \mathrm{nmol})$ was substituted in the incubation mixture described for (1) for the $\left[{ }^{32} \mathrm{P}\right] \mathrm{DHAP}$ and palmitoyl CoA. (4) $0.1 \mathrm{mg}$ NADPH was added to the mixture described in (3). (5) The mixture was the same as described in (1), but the substrate was $\left[{ }^{32} P\right] G-3-P$. (6) Standard, non-radioactive phosphatidic acid. (7) Standard acyl G-3-P. (8) Standard acyl DHAP. 
Table 2. Relative rate of acylation of DHAP With different aCyl CoA's in brain MICROSOMES

\begin{tabular}{cccccccc}
\hline Fatty acyl CoA & $16: 0$ & $18: 0$ & $18: 1$ & $18: 2$ & $20: 4$ & $22: 4$ & $22: 6$ \\
\hline$\%$ & 100 & 65 & 41 & 51 & 3 & 3 & 1 \\
\hline
\end{tabular}

The incubation conditions are those described in Methods and the reaction was run for $15 \mathrm{~min}$ at $\mathrm{pH} 7.4$. Instead of palmitoyl $\mathrm{CoA}$, the various acyl CoA's described above were substituted at approx $40 \mu \mathrm{M}$. The data are given as a percentage of the activity obtained with palmitoyl CoA, which is highest $(0.5 \mathrm{nmol} / \mathrm{min} / \mathrm{mg}$ protein).

Previously, using the common substrate inhibition criteria, it was shown that in guinea pig liver, the mitochondrial DHAP acyl transferase was different than the G-3-P acyl transferase, but that the microsomal enzyme may use both DHAP and G-3-P as substrates (HAJRA, 1968a). Similarly, SChLosSman \& BELL (1976) showed recently that in adipose tissue microsomes, the G-3-P acyl transferase and DHAP acyl transferase had very similar properties, and they concluded that the same enzyme was probably catalyzing both the reactions. The results presented here show that the G-3-P acyl transferase and the DHAP acyl transferase in the brain microsomal fraction have different properties. The difference in pH optima (Fig. 2) and the differential effect of cholate (Fig. 8) point toward the existence of two distinct enzymes. In addition, the competition studies (Fig. 7) show that DHAP acylation at pH 5.4 is not inhibited by an increasing concentration of G-3-P, and at $\mathrm{pH} 7.5$ only slight inhibition is observed. These results are consistent with the assumption that the DHAP acyl trans-

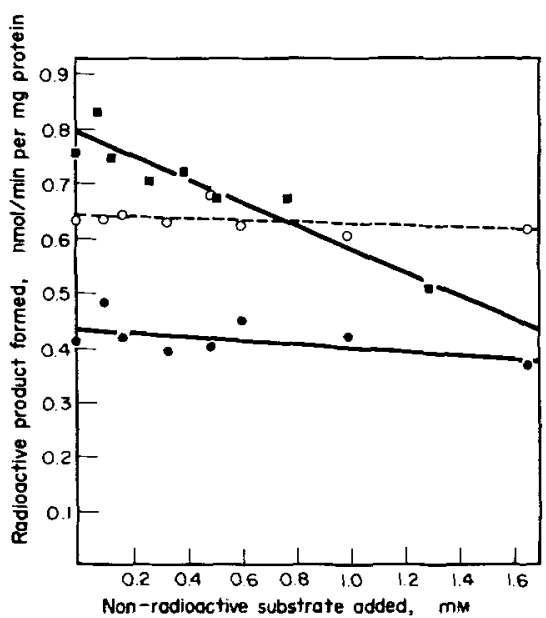

FIG. 7. Effect of the addition of non-radioactive G-3-P on the acylation of $\left[{ }^{32} \mathrm{P}\right] \mathrm{DHAP}$ in brain microsomes. The incubation mixture contained $2-2.5 \mathrm{mM}$ of radioactive substrates, i.e. either $\left[{ }^{32} \mathrm{P}\right]$ DHAP $(\mathrm{pH} 5.4 \mathrm{O}-\mathrm{O}$ and $\mathrm{pH} 7.4$ - - ) or $\left[{ }^{32} \mathrm{P}\right] \mathrm{G}-3-\mathrm{P}$ (pH 7.4, $\left.\square-\square\right)$, palmitoyl CoA (0.1 $\mathrm{mg}$ ), brain microsomes $(0.2 \mathrm{mg}$ protein), bovine serum albumin (2 $\mathrm{mg}), \mathrm{MgCl}_{2}(8 \mathrm{mM}), \mathrm{NaF}$ ( $8 \mathrm{~mm}$ ), and varying concentrations of non-radioactive G-3-P or DHAP as indicated in the Figure. The mixtures were incubated for $15 \mathrm{~min}$ at $37^{\circ} \mathrm{C}$ and the amount of radioactive lipid formed was determined as described under Methods. ferase is a separate enzyme which will not accept G-3-P as substrate. The G-3-P acyl transferase, however, may accept DHAP as substrate since an inhibition of G-3-P acyl transferase activity by DHAP was observed (Fig. 7).

The results presented in this paper show that enzymes necessary for the biosynthesis of phosphatidic acid via acyl dihydroxyacetone phosphate are present in rat brain. It has been previously shown that the enzymes for the biosynthesis of glycerol ether lipids from acyl DHAP are also present in brain (HAJRA, 1969; HAJRA, 1970). This raises the question of whether the acyl DHAP pathway in brain is used only for the biosynthesis of glycerol ether lipids or is also important for diacyl phosphoglyceride biosynthesis. It has been previously assumed that the G-3-P pathway is solely used for phosphoglyceride biosynthesis in brain (PossmaYer et al., 1973). However, the above results show that diacyl glycerolipids in brain are biosynthesized by both the pathways. It is possible that the major portion of brain phosphoglycerides are biosynthesized via the G-3-P pathway as the rate of acylation of G-3-P is $1.5-2 \mathrm{X}$ that of DHAP acylation (Figs. 7 and 8). However, it should be pointed out that the in vitro acylation activity depends entirely on the incubation conditions used.

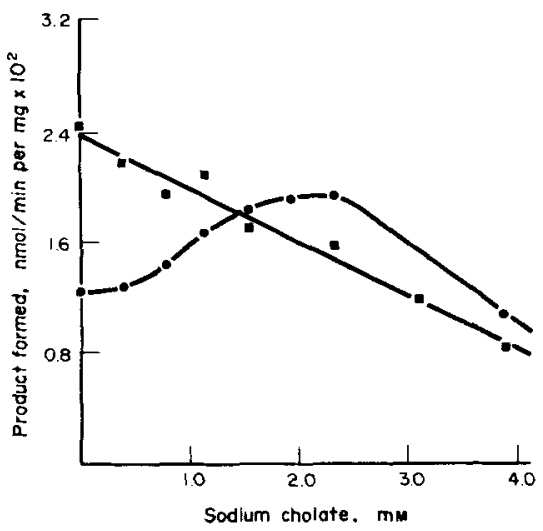

Fig. 8. The effect of Na cholate on the enzymatic acylation of DHAP (- - ) and G-3-P ( - homogenate. Rat brain homogenate was preincubated at pH 7.4 for $5 \mathrm{~min}$ with all the other constituents of the standard incubation mixture (including the specified amounts of cholate) except palmitoyl $\mathrm{COA}$ and the radioactive substrate. These two were added to start the reaction which ran for $15 \mathrm{~min}$. The extraction and counting procedures were described in Methods. 
For example, in the absence of bovine serum albumin DHAP acylation activity $(0.216 \mathrm{nmol} / \mathrm{min} / \mathrm{mg}$ protein) is higher than the G-3-P acylation activity $(0.109 \mathrm{nmol} / \mathrm{min} / \mathrm{mg}$ protein). The same is true in the presence of a low concentration of sodium cholate (Fig. 8). In addition, preliminary results suggest that the G-3-P pathway enzymes and the acyl DHAP pathway enzymes may be localized in different subcellular compartments (see above). Experiments using D- $\left[3-{ }^{3} \mathrm{H}\right]$ glucose incorporation into glycerolipid in different systems showed that a significant fraction of the diacyl glycerolipid and all of the glycerol ether lipid are biosynthesized via the acyl DHAP pathway (Pollock et al., 1976; HaJRA, 1977). In view of these facts, the assumption that brain phosphoglycerides are biosynthesized only via the G-3-P pathway must be called into question. It seems plausible to assert that these two pathways for glycerolipid biosynthesis are operating side by side and are used either to make different lipids on the same membrane or to make lipids for different intracellular membranes. Further work is necessary to answer these questions satisfactorily.

Acknowledgement-This work was supported by Grant NS 08841 from the National Institute of Health, U.S. Public Health Service.

\section{REFERENCES}

Ballou C. E. \& Fischer H. O. L. (1956) J. Am. Chem. Soc. 78, 1659-1661.

Buigh E. G. \& Dyer W. J. (1959) Can. J. Biochem. 37, 911-917.

BÜCHER T. \& HOHORST H. J. (1963) in Methods of Enzymatic Analysis (BERGMEYER HANS-UlRich, ed.) 2nd edn, pp. 246-252. Academic Press, New York.

Chae K., Piantadosi C. \& Snyder F. (1973) J. biol. Chem. 248, 6718-6723.

Clark J. B. \& Nicklas W. J. (1970) J. biol. Chem. 245, 4724-4731.

deDuve C., Pressman B. C., Gianetro R., Wattiaux R. \& Appelmans F. (1955) Biochem. J. 60, 604-617.

Dixon M. \& WebB E. C. (1964) in Enzymes, 2nd edn, pp. 84-87. Academic Press, New York.

Eichberg J., Whittaker V. P. \& Dawson R. M. C. (1964) Biochem. J. 92, 91-100.

Fleming P. J. \& HajRa A. K. (1977) J. biol. Chem. 252 $1663-1672$.

Gaunt G. L. \& DeDuve C. (1976) J. Neurochem. 26, 749-759.

Glinn I. M. \& Chappell J. B. (1964) Biochem. J. 90, $147-149$

HaIRa A. K. (1968a) J. biol. Chem. 243, 3458-3465.

HAJRA A. K. (1968b) Biochem. biophys. Res. Commun. 33, 929-935.
Hajra A. K. (1969) Biochem. biophys. Res. Commun. 37, 486-492.

Hajra A. K. (1970) Biochem. biophys. Res. Commun. 39, 1037-1044.

HajRA A. K. (1974) Lipids 9, 502-505.

HajRA A. K. (1977) Biochem. Soc. Trans. 5, 34-36.

Harra A. K. \& AgranofF B. W. (1968a) J. biol. Chem. 243, $1617-1622$.

Hajra A. K. \& Agranoff B. W. (1968b) J. biol. Chem. 243, 3542-3543.

HaR wood J. L. \& Hawthorne J. N. (1969) J. Neurochem. 16, $1377-1387$.

HoHORST H. J. (1963) in Methods of Enzymatic Analysis (Bergmeyer Hans-Ulrich, ed.), 2nd edn, pp. 215-219. Academic Press, New York.

Jones C. L. \& HAJRA A. K. (1977) Biochem. biophys. Res. Commun. 76, 1138-1143.

Jungalwala F. B. \& Dawson R. M. C. (1971) Biochem. J. 123, 683-693.

KENNEDY E. P. (1962) Harvey Lec. 57, 143-171

Kuwahara S. S. (1972) J. Neurochem. 19, 641-651.

LABelle E. F,, Jr. \& HajRA A. K. (1972a) J. biol. Chem. 247, 5825-5834.

LaBelle E. F., Jr. \& Hajra A. K. (1972b) J. biol. Chem. 247, 5835-5841.

LABelle E. F., It. \& HajRA A. K. (1974) J. biol. Chem. 249, 6936-6944.

Lamb R. G. \& Fallon H. J. (1976) J. Lipid Res. 17, 406-411.

MARtensson E. \& Kanfer J. (1968) J biol Chem. 243, 497-501.

McMurray W. C., Strickland K. P., Berry J. F. \& RosSITER R. J. (1957) Biochem. J. 66, 634-644.

MEYeRHOF O. \& LOHMANN K. (1934) Biochem. Z. 271, 89-110.

Miller E. K. \& Dawson R. M. C. (1972) Biochem. J. 126, 805-821.

Novikoff A. B., Novikoff P. M., Davis C. \& Quintana N. (1973) J. Histochem. Cytochem. 21, 737-755.

Okuyama H., Landos W. E. M. Christie W. W. \& GunSTONE F. D. (1969) J. hiol. Chem. 244, 6514-6519.

Olafson R. W., Drummond G. I. \& LeE J. F. (1969) Can. J. Biochem. 47, 961-966.

Pollack R. J., Hajra A. K. \& Agranoff B. W. (1975) Biochem. biophys. Acta 380, 421-435.

Pollack R. J., Hajra A. K. \& Agranoff B. W. (1976) J. biol. Chem. 251, 5149-5154.

Possmayer F., Meiners B. \& Mudd J. B. (1973) Biochem. J. 132, 381-394.

Puleo L. E., RAo G. R. \& Reiser R. (19J0) Lipids 5, $770-775$.

Sánchez de Jimínez E. \& Cleland W. W. (1969) Biochem. biophys. Acta 176, 685-691.

Schlossman D. M. \& Bell R. M. (1976) J. biol. Chem. 251, 5738-5744.

Seubert W. (1960) Biochem. Prep. 1, 80-83.

Van Den Bosch H. (1974) A. Rev. Biochem. 43, 243-277.

Williams C. H. \& Kamin H. (1962) J. biol. Chem. 237(2). $587-592$.

Wykle R. L., Piantadosi C. \& Snyder F. (1972) J. biol. Chem. 247, 2944-2948. 